\title{
Acerca de Juana Francés
}

\author{
Laura Fernández Orgaz \\ Doctorada Historia del Arte. UNED
}

\begin{abstract}
RESUMEN ABSTRACT
Partiendo de la desigual visibilidad de

Taking into account the poor visibility of Juana Francés frente al resto de Juana Francés compared to the rest of her generation colleagues, the article reflects on some of the causes that compañeros de su generación, el artículo considera algunos de los factores que provocaron esta injusta situación. Así provoked this unfair situation. In addition mismo se aborda un recorrido por la intensa y variada trayectoria creativa de la to that, the article explores the intense and diverse artistic career including her most artista que incluye sus etapas más significant stages.
\end{abstract} significativas analizadas.

Palabras clave:

Key words:

Visibilidad, trayectoria artística.

Visibility, artistic career.

Antes de pasar a analizar la trayectoria artística de Juana Francés, me gustaría poner de manifiesto una cuestión más que evidente: la escasa visibilidad de Juana Francés como artista.

Me atrevería a afirmar que Juana Francés es, sin duda, uno de los miembros menos conocidos del grupo El Paso, y seguramente, uno de los menos expuestos. Este es un hecho que aún hoy todavía se puede constatar. El 27 de mayo del 2004, en un periódico de tirada nacional hace referencia a una exposición del grupo El Paso realizada en una galería de Madrid, el periodista cita en su crónica a todos sus fundadores y omite - ¿por olvido?, ¿por desconocimiento?- el nombre 


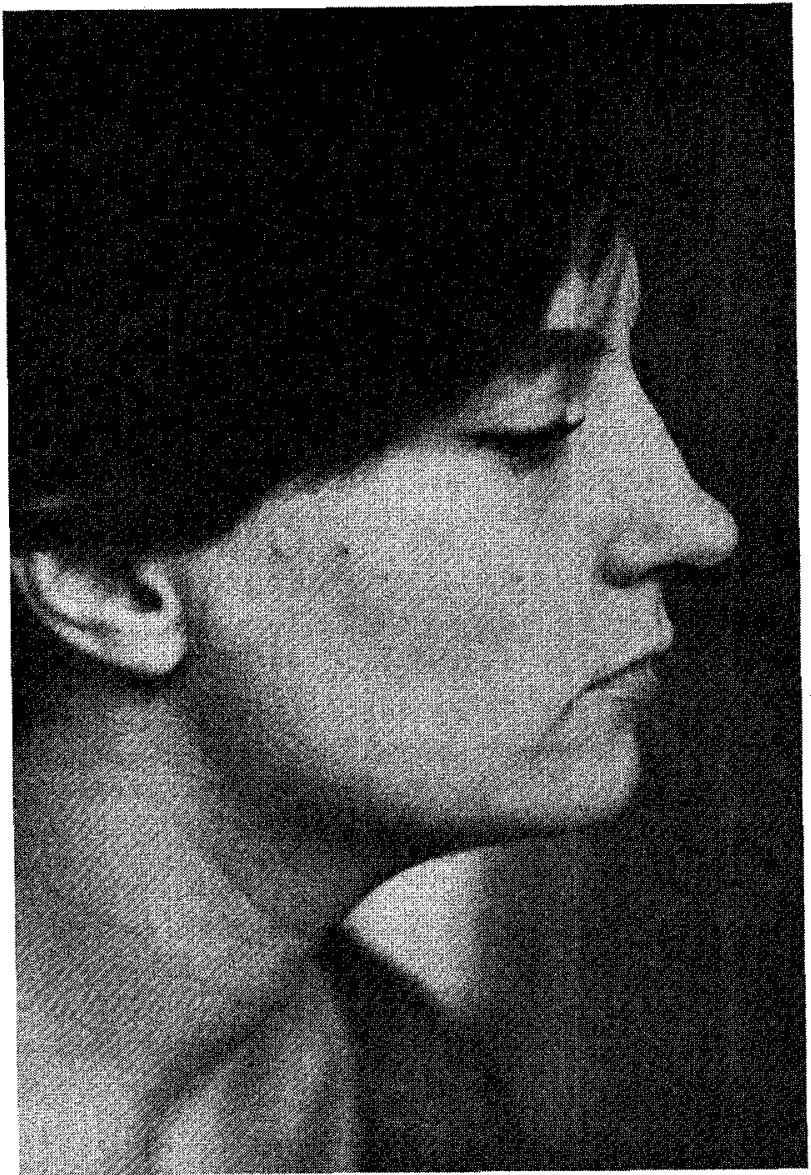

Fig. 1. Juana Francés.

de la única mujer que junto al resto de artistas contribuyó a la creación del grupo. Mi sorpresa no acaba ahí cuando al consultar diferentes fuentes sobre El Paso, el nombre de Juana Francés figura rigurosamente en los textos, no así su imagen. Desconozco los motivos pero sorprende que frente a numerosas fotos de grupo de sus compañeros iniciales, la imagen de Juana fotografiada junto al resto de artistas que en 1957 se agruparon para crear El Paso, es muy escasa.

El número de exposiciones que Juana Francés llevó a cabo en vida o después de su muerte tampoco mejoran el panorama. Su proyección exterior en tiempos del Paso durante los años de la política cultural de promoción internacional que González Robles realizó con estos y otros artistas del momento, aunque fecunda, le po- 


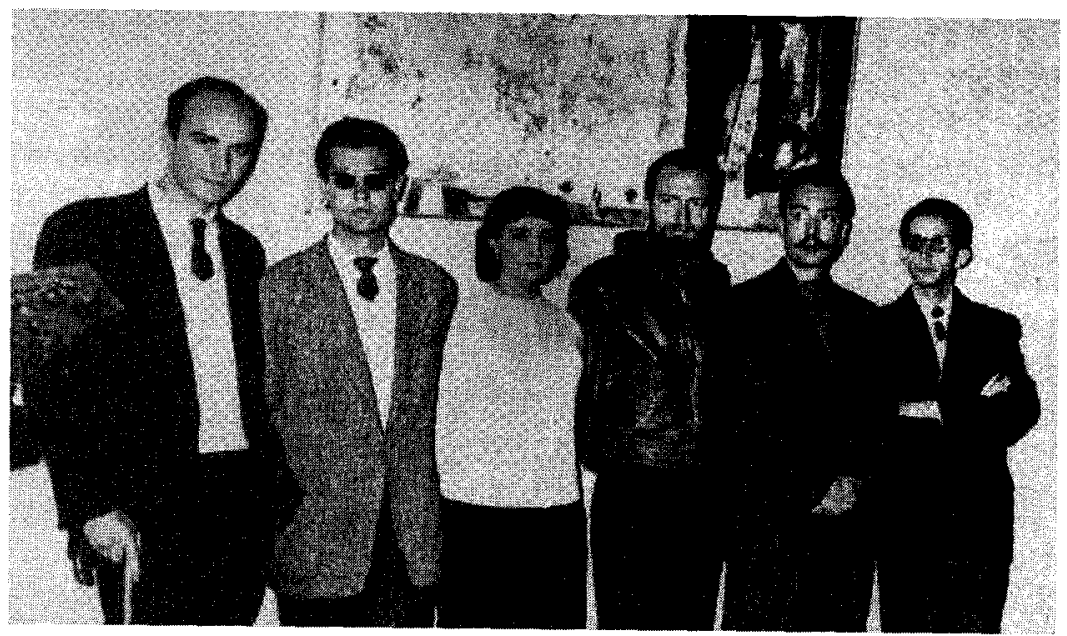

Fig. 2. Una de las pocas imágenes de Juana Francés con algunos de sus compañeros de El Paso.

nen en clara desventaja frente al resto de sus compañeros. Por citar algunos ejemplos de su presencia en colectivas internacionales, en 1954 participa junto a Francisco Farreras y Nestor Basterretxea en la Bienal de Venecia; en 1960 forma parte de la exposición Before Picasso, after Miró en el Solomon R. Guggenheim Museum de Nueva York; en 1961 en el Palais de Beaux-Arts de Bruselas, y en 1962 en la Tate Gallery de Londres en la exposición titulada Modern Spanish Painting. ${ }^{1}$

Estos datos, que sin duda son positivos, pues es prácticamente la única artista española que expone en el extranjero en ese período, dejan de ser tan optimistas cuando se comparan con la intensa presencia de la mayoría de sus colegas de grupo en exposiciones internacionales por Europa, Estados Unidos y Latinoamérica.

Desafortunadamente la tenue visibilidad de Juana Francés poco cambia cuando muere en 1990. Se han realizado muy pocas exposiciones individuales sobre su obra desde entonces, aunque sí ha estado presente en algunas colectivas. Este dato se constata en la "queja" que Arcadio Blasco manifiesta en el catálogo de la exposición homenaje a Juana Francés que él mismo comisarió en 1995, en Alicante $^{2}$. En el texto de presentación, Blasco se lamenta de la imposibilidad de haber organizado la gran exposición que Juana se merecía, mayor y más completa de la

1 Tusell García, G:. «La proyección exterior del Arte Abstracto Español en tiempos del Grupo El Paso", en: En el tiempo de El Paso, Madrid, Centro Cultural de la Villa, 2002, pág. 102-103.

2 Blasco, A.: Juana Francés 1924-1990: exposición homenaje, Alicante, Ayuntamiento de Alicante, Concejalía de Cultura, 1995, pág. 7. 


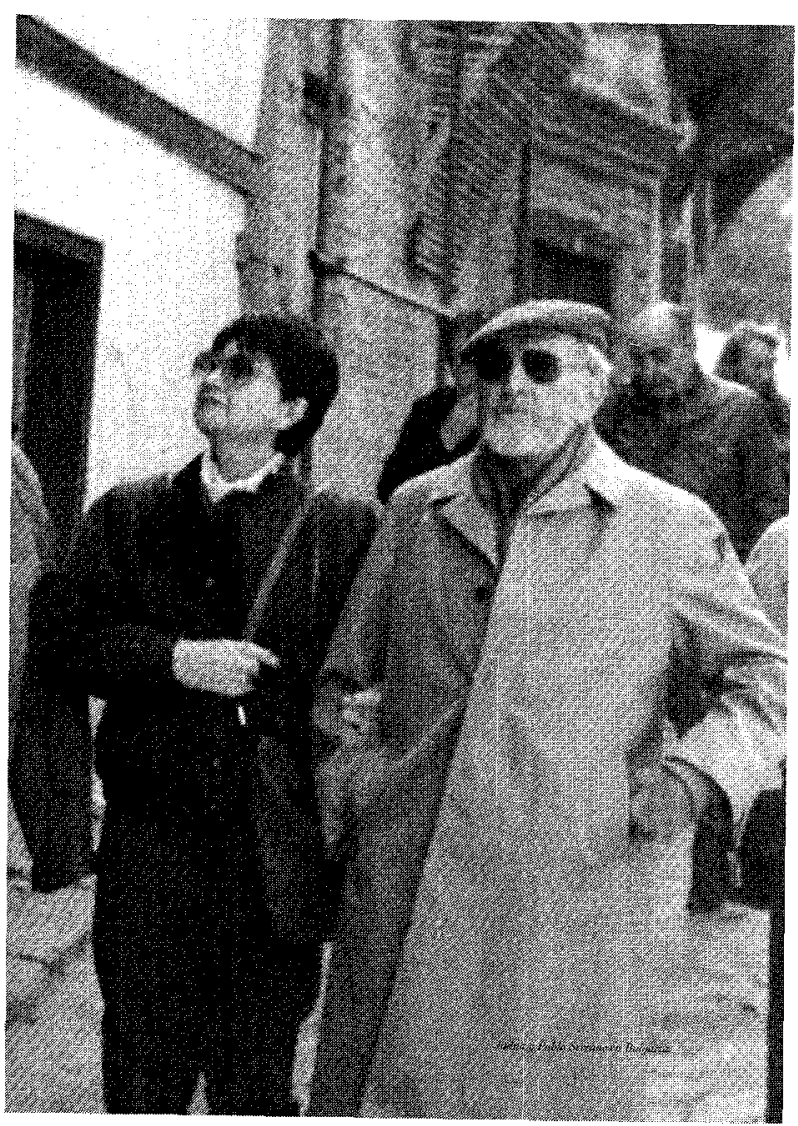

Fig. 3. Juana Francés junto a Pablo Serrano en un viaje a Bulgaria.

que finalmente se hizo en Alicante. De sus palabras se deduce una lamentable falta de interés por parte de las instituciones ante la obra de Juana Francés.

En mi opinión tres son las razones que han contribuido a minimizar la presencia de J. Francés y a infravalorar su obra frente a otros compañeros de generación. Por un lado, la situación social de la mujer española en la década de los 50, por otro, el machismo arraigado en la comiunidad artística de esa época, y por último, su matrimonio con el escultor Pablo Serrano.

En los años 50 la mujer española estaba dedicada casi con exclusividad a las labores del hogar y la crianza de los hijos. Las estadísticas del número de mujeres universitarias en esos años son francamente bajas. 
Cuando Juana Francés comienza sus estudios en la Real Academia de Bellas Artes de San Fernando de Madrid, Francisco Farreras, compañero y amigo de la artista alude a la escasa presencia de compañeras en «un terreno reservado a los hombres" y cuenta como un crítico de la época se refiere a Juana Francés y otras artistas del momento con el despectivo sobrenombre del «grupo del ovario" ${ }^{3}$. De las propias palabras de Francisco Farreras al hablar de su amiga se detecta un profundo afecto, y paradójicamente, un sesgo muy machista - ¿inconsciente?cuando afirma que «ante cualquiera de las obras que caracterizan sus diferentes épocas y períodos, nada podría hacer pensar que detrás de la fuerza expresiva y plástica de esas potentes composiciones realizadas con pintura y arena exista una presencia femenina". Es evidente que para Farreras la fuerza expresiva es un atributo exclusivamente del varón. Este tipo de testimonios dan fe de cuál era la mentalidad de los artistas de la generación de Juana.

No hay duda de que durante mucho tiempo el panorama artístico nacional e internacional ha sido - ilo sigue siendo?-dominado por los hombres y su acceso a él, por parte de las mujeres, llegó a ser casi infranqueable. Lamentablemente Juana Francés tuvo la oportunidad de comprobarlo en primera persona, llegando a ser claramente una víctima de parte de la comunidad artística española del momento al verse obligada a abandonar El Paso como consecuencia del rechazo de algunos de sus compañeros. Martín Chirino lo explica bien claro en una entrevista realizada por Javier Tusell para una exposición antológica de El Paso «algunos tenían esa sensación de que Juana Francés no era una artista adecuada para ser miembro del grupo. Y ahí hubo una primera disensión, y a partir de eso se creó una especie de tensión y deciden que Juana Francés no esté. Y entonces, claro, Pablo Serrano también se sintió mal y abandonó el grupo...» ${ }^{4}$. ¿El trabajo de Juana queda en entredicho por una falta real de calidad? $\mathrm{O}$ ¿se cuestiona su calidad artística por su condición de mujer...?

Otro factor, que en mi opinión, contribuyó a desencadenar la situación que Juana Francés vivió a lo largo de su carrera, fue su matrimonio con Pablo Serrano.

La «invisibilidad persistente como sujeto creador» 5 de Juana Francés es una experiencia compartida por otras artistas de la época. Juana no fue la única artista a la sombra de su marido, es el caso también de Amalia Avia, mujer de Lucio Muñoz o de Angeles Santos, casada con Julián Grau Sala, que prácticamente abandonaron su carrera artística para dedicarse a las obligaciones familiares. No

3 Farreras, F.: Juana Francés 1924-1990: exposición homenaje, Alicante, Ayuntamiento de Alicante, Concejalía de Cultura, 1995, pág. 10.

4 TUSELL, J.: «Entrevista a Martín Chirino», en En el tiempo de El Paso, Madrid, Centro Cultural de la Villa, 2002, pág. 126.

5 Mayayo, P.: Historia de mujeres, historias del arte, Madrid, Cátedra, 2003, pág. 21. 
obstante, y aunque Juana si pudo desarrollar un trabajo intenso y prolífico, su carrera fue eclipsada por su unión con el escultor aragonés. No significa esto que si no se hubiera casado con Serrano todo habría sido "coser y cantar" pero desde luego creo que este es un factor interesante a tener presente.

La pareja se conoce en 1956 cuando Pablo Serrano es casi veinte años mayor que Juana. En el momento de formación de El Paso, Pablo Serrano cuenta ya con una sólida proyección artística adquirida en sus años de residencia en Latinoamérica. Artísticamente, la juventud de Juana y su condición de mujer de los años cincuenta, le pusieron en franca desventaja ante Pablo Serrano, -hombre maduro y gran escultor-, relegándole a un segundo plano. Llama la atención que en el catálogo de la casa de subastas Finarte, editado en 1997 y realizado con motivo de una exposición sobre El Paso, el primer dato biográfico que aparece sobre Juana Francés es: «Pintora casada con el escultor Pablo Serrano» 6 mientras que en la ficha biográfica de Pablo Serrano la referencia a su matrimonio con Juana Francés aparece en el tercer párrafo. Aunque las razones que empujaron a Juana a la sombra de su marido merecerían ser estudiadas con mayor profundidad, simplemente me limito tan sólo a hacer hincapié en un dato que considero que no es baladí.

\section{EN TORNO AL ARTE DE JUANA FRANCÉS}

Si hubiera que definir de manera breve la obra de Juana Francés, dos son las palabras que, en mi opinión, podrían utilizarse: búsqueda constante y versatilidad.

Una vez que Juana Francés se decanta por la vocación artística, practicaría, desde sus inicios profesionales, una exploración incansable que le llevaría a lo largo de su carrera a deambular por diferentes lenguajes, materiales, asuntos o géneros. La figuración, la abstracción, la materia, el color, el paisaje, o el ser humano fueron algunos de los aspectos que interesaron a la artista y que dieron lugar, en diferentes momentos creativos, a una obra diversa, intensa, y sobre todo, muy coherente. Puesto que «la neutralidad de las imágenes artísticas no existe» ${ }^{7}$, en mi opinión, al estudiar la obra y la vida de Juana Francés se detecta una continua reivindicación por ser ella misma, por autofianzarse como artista, por encontrar a través de su arte un espacio como persona, y un hueco como artista frente a los demás.

Ante la posición vulnerable que le tocó vivir como mujer artista, Juana reacciona de manera visceral y hace gala de una fuerte personalidad artística a la hora

${ }^{6}$ EL PASO: Revisión del Grupo El Paso en su cuarenta aniversario. Madrid, Finarte España, 1997, pag. 22

7 Ibid., pág. 163. 
de crear estilos propios. Según Román de la Calle «la artista solía insistir en la necesidad que sentía de pintar para mejor comprenderse ${ }^{8}$. Es como si Juana utilizara el arte de manera terapéutica para reafirmarse, para construir y representar sus mundos particulares, dotados con el sello de una mirada muy personal. Su obra es como una ventana por la que se asoma su arte y su alma.

Aunque parte de la obra de Juana Francés es contemporánea a la irrupción del movimiento feminista y a las experiencias de una serie de mujeres artistas que luchan por su justa visibilidad y sus derechos, su arte no parece adscribirse a ninguno de estos postulados. Sin embargo, en algunos períodos creativos, sus obras revelan una postura crítica que arremete de manera simbólica contra ciertos aspectos del sistema social imperante. Me refiero en concreto al trabajo que desarrolla a partir de 1963 en la serie El hombre y la ciudad y otras series posteriores.

A continuación se describe de manera sucinta las etapas más significativas que recorrió artísticamente Juana Francés para después analizar ejemplos de algunos de estos momentos. Es interesante recalcar que a lo largo de su carrera, la artista se acercó de manera casi cíclica tanto a la abstracción como a la figuración, entendiéndose ambos conceptos no de manera antitética sino complementaria, y como opciones diferenciadas de planteamientos que tienen mucho en común. Pues «la abstracción y la figuración, en sí mismas no comportan una tendencia, una idea, ni una actitud, sino un medio, un vehículo, y una forma de desarrollar una tendencia” ${ }^{9}$. Así que en cada etapa, se acercaría al lenguaje que más le satisficiera para materializar sus intereses e ideas.

La primera etapa de la obra de Juana Francés entre 1950 y 1953 se caracteriza por la presencia de una figuración hierática geometrizante, con temas de corte muy tradicional. Posteriormente, en 1956 comienza a experimentar con la abstracción. En 1957 tras la fundación de El Paso, comienza una etapa adscrita al informalismo matérico. Ya en los primeros sesenta, se insinúa en su obra una paulatina vuelta a la figuración que desemboca más adelante en la serie El hombre y la ciudad, momento de crítica, y pesimismo existencial. Este tipo de asunto evolucionaría posteriormente en la serie Torres-Participación y más tarde en la serie Estructuras, hasta 1979.

A partir de la década de los ochenta retorna a una abstracción de gran lirismo, plena de color y vitalidad, con referencias a paisajes, fondos submarinos, cometas, etc.

${ }^{8}$ CALLE, R. de la: «Las miradas de Juana Francés» en Juana Francés 1924-1990: exposición homenaje, Alicante, Ayuntamiento de Alicante, Concejalía de Cultura, 1995, pág. 19.

- NIETO ALCALDE, V.: "Juana Francés y las raíces surrealistas del Informalismo", en Juana Francés 1924-1990: exposición homenaje, Alicante, Ayuntamiento de Alicante, Concejalía de Cultura, 1995, pág. 30. 


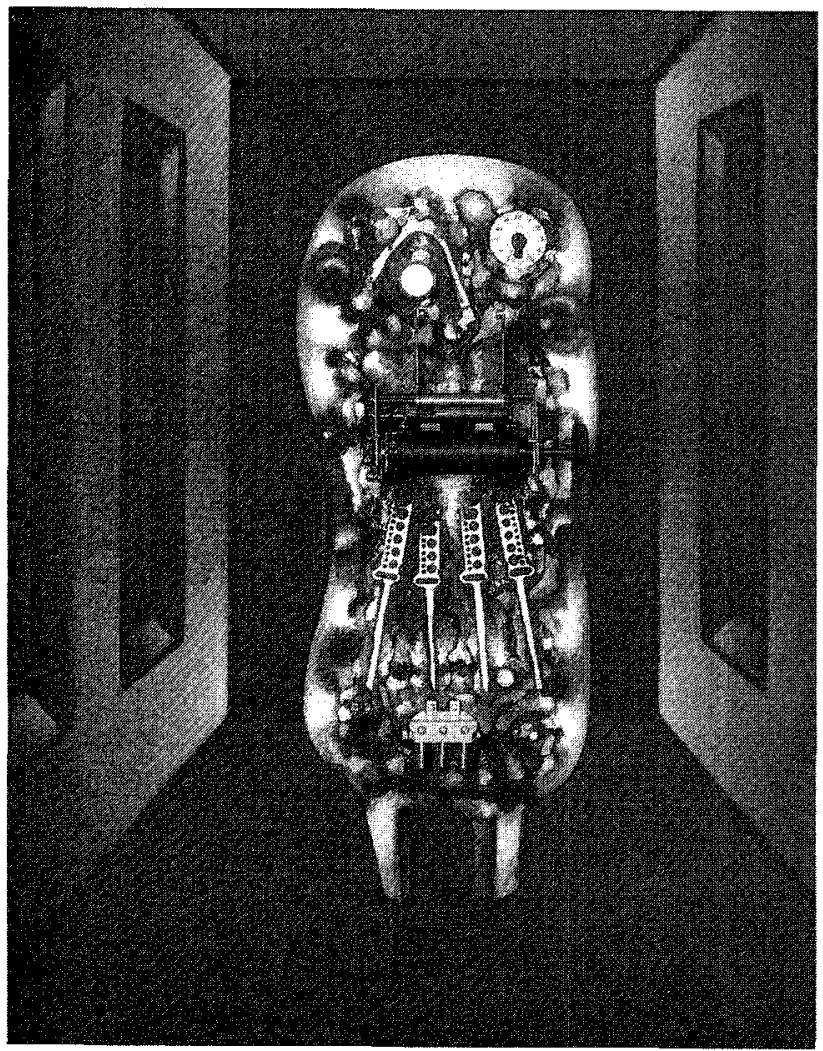

Fig. 4. A la espera, 1976.

Un aspecto relevante a destacar en esta trayectoria son los períodos de transición entre una etapa y otra que denotan rastreos, toma de decisiones y que anuncian los cambios que después se desarrollarán en diferentes series.

\section{OBSERVANDO SUS OBRAS}

En su primera etapa es evidente que la personalidad artística de Juana Francés se está fraguando. Estilísticamente se puede intuir la influencia de algunos de sus maestros de la Academia de Bellas Artes de San Fernando - como Vázquez Díaz-.En los ejemplos que siguen a continuación podemos observar que la artista trata temas tradicionales, «adecuados» y «aconsejables» para una mujer que pretendía ser artista en aquellos esos años. 


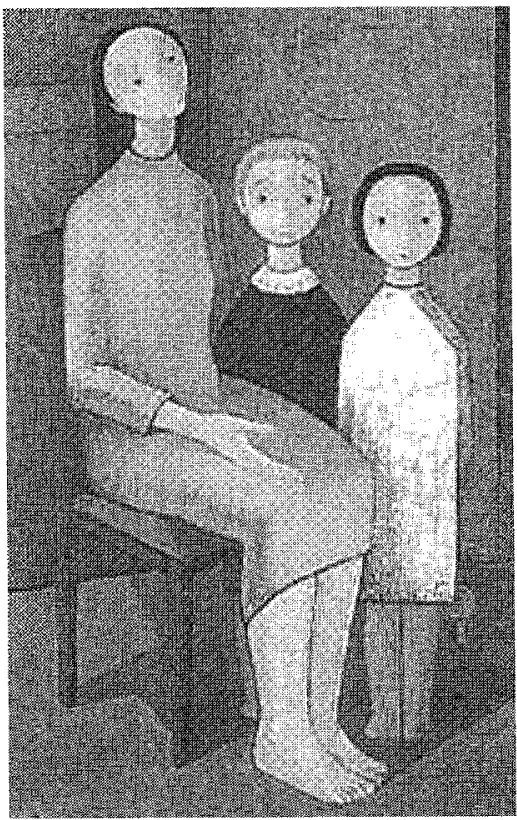

Fig. 5. Mujer con dos niños, 1952.

En Mujer con dos niños, el predominio de formas esquemáticas y lineales permite afirmar que la artista conoce los lenguajes de las vanguardias artísticas. La mujer tiene un aire ausente y melancólico acentuado por la posición de su cabeza. Junto a ella aparecen dos niños, que con tono serio, posan hieráticos mirando de frente.

El asunto, de corte muy tradicional, está tratado de manera fría y distante, con aires de cierta modernidad. Seguramente no sería lo que en el entorno académico se pudiera esperar de semejante asunto realizado por la mano de una mujer artista (presumiblemente debiera haber sido una escena muy "femenina", más bien cursi y ñoña). Pero a pesar de todo, las obras hablan, y de su lectura se pueden entresacar ciertos estereotipos sexistas, anclados todavía en nuestra sociedad actual, y sin duda, mucho más arraigados en los años de juventud de Juana.

Figura de hombre, de 1952, en el mismo estilo que la anterior, nos muestra a un varón en primer plano, hierático, serio, casi retador. La manera de representar a este hombre y la mujer de la obra anterior, indica de manera sutil, qué atributos aplica la joven artista a uno y a otra. La mujer es frágil, el hombre rotundo; ella está pensativa y ausente, él observante. La mujer aparece con dos niños, presumiblemente sus hijos - labor exclusiva de la mujer de entonces- en el interior de lo que 


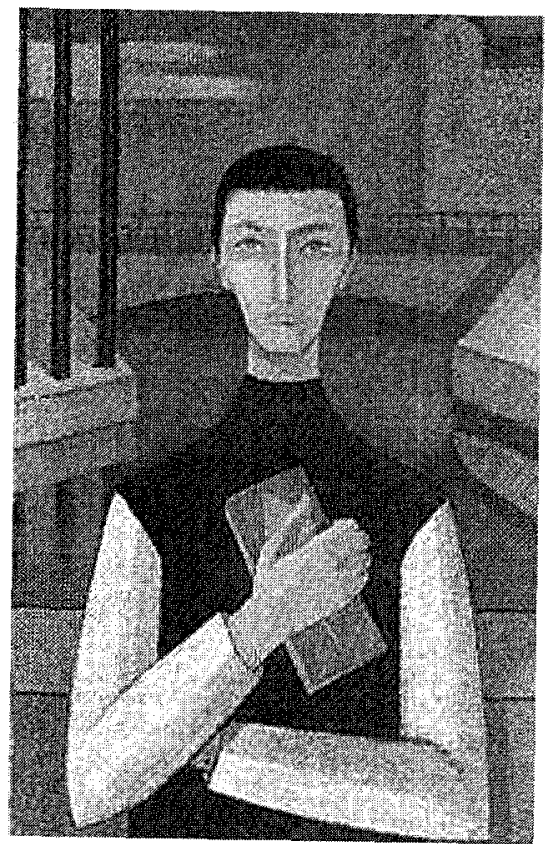

Fig. 6. Figura de hombre, 1952.

puede ser una casa (su entorno más común). En contraposición, el hombre lleva en sus manos un libro - actividad intelectual reservada al varón-y está al aire libre, en un fondo que parece un pueblo.

Otros ejemplos de estos mismos años no hacen sino corroborar lo anteriormente expuesto. Desnudo de mujer nos presenta a una mujer objetualizada y en actitud sumisa, con un aire lineal, lánguido y muy pasivo y Pareja con niño deja entrever nuevamente los roles que socialmente se atribuyen al hombre y a la mujer. Esto se revela en la propia posición de los protagonistas; la mujer, con aire dócil y sumiso, sentada y con una flor en la mano. El hombre, de pié, con actitud protectora, se sitúa detrás de la mujer, y agarra suavemente el hombro de la niña.

En cualquier caso, tras estos primeros balbuceos artísticos, parece que a la Juana Francés de 21 años, no le satisface este estilo y un par de años después, y de manera valiente, se produce un cambio radical: la abstracción.

Un dato importante a tener en cuenta fue la asistencia de Juana Francés al curso de Arte Abstracto impartido en Santander en 1953. A partir de ese momento, comienza el abandono de lo figurativo que le lleva a un momento de transición, en el que practica la pintura abstracta, en un primer momento de tipo geométrico y que 


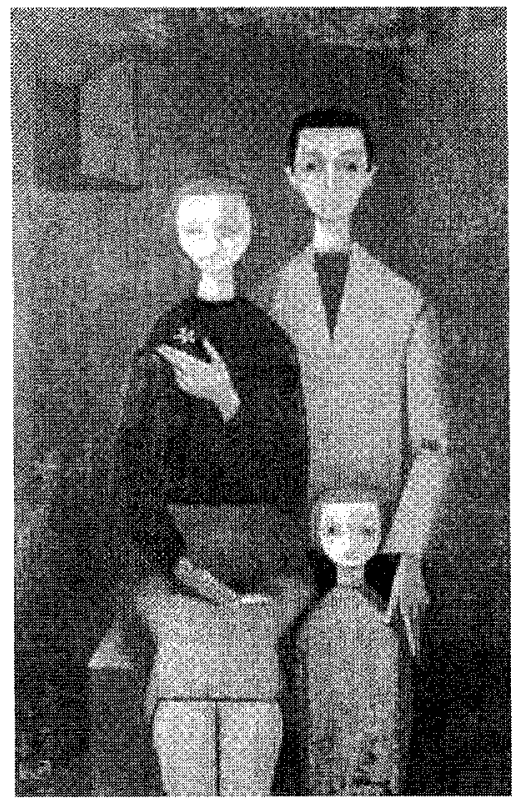

Fig. 7. Pareja con niño, hacia 1950.

desemboca paulatinamente en la abstracción matérica. Es el momento en que se adscribe al grupo El Paso.

Sin título, realizada en 1957 pertenece al momento del informalismo matérico. Juana Francés se ha zambullido de lleno en la abstracción y comienza a investigar con materiales como la arena. Aquí se puede intuir a una artista más segura. Incorpora un lenguaje gestual, decidido y con carácter propio. Las líneas verticales y horizontales que conviven con pequeñas manchas de color, denotan un cierto poso de la abstracción geométrica. Con el tiempo, las manchas, en detrimento de las líneas, irán aumentando de tamaño para adueñarse de toda la superficie del lienzo y proclamarse en las verdaderas protagonistas, como ocurre en Sapo panderetero, de 1961. La textura ahora se ha convertido en un elemento fundamental de la obra. El trazo es más rotundo, y está lleno de fuerza y energía.

Su informalismo matérico se ha ido concretando, ha ido tomando cuerpo, y desde luego, es equiparable en calidad artística a cualquier obra contemporánea de sus colegas de EI Paso (que poco antes le habían presionado para abandonar el grupo). Es un momento de gran dinamismo y vigor que contrasta con la ingenua languidez de su etapa anterior. 


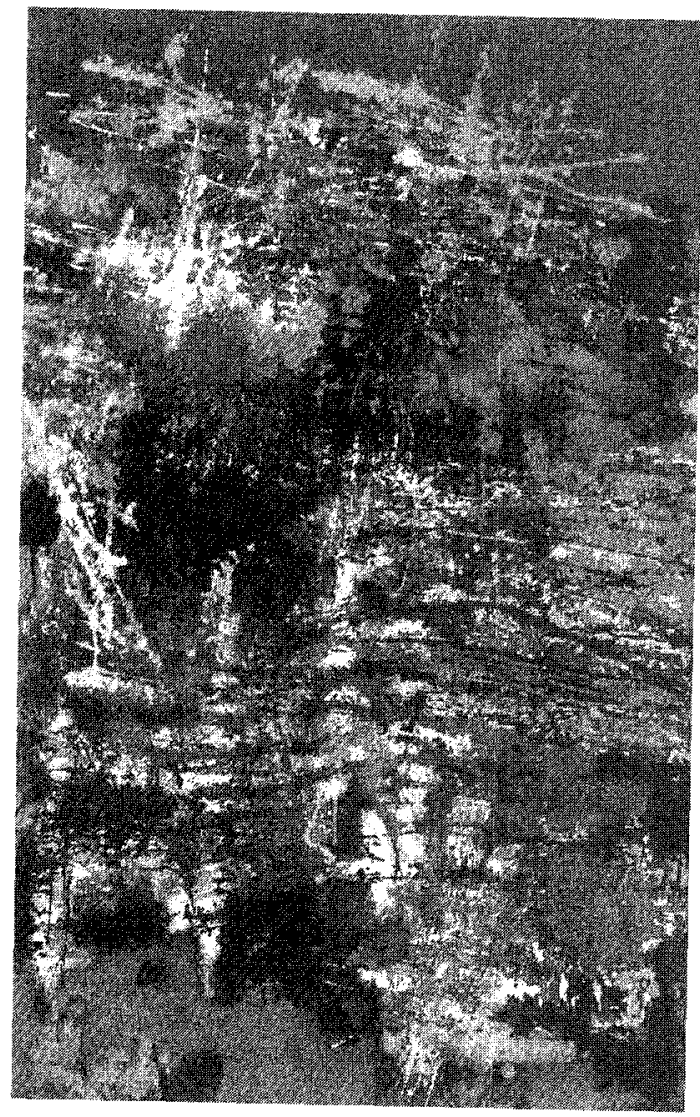

Fig. 8. Sin título, 1957.

Abordar estas obras ( $u$ otras) desde un feminismo esencialista, resulta incoherente y muy forzado. En mi opinión, es obvio que Juana Francés no utiliza en estos cuadros una «iconología vaginal» como definieron Judy Chicago y Miriam Schapiro en Estados Unidos pocos años después de la realización de estas piezas. Efectivamente, en esta y otras etapas abstractas posteriores, la artista a veces emplea una imagen central o utiliza formas ovoides, que según Chicago y Schapiro era, entre otros, un elemento recurrente en el lenguaje de muchas artistas, que determinaba la necesidad de explorar su identidad y su sexualidad ${ }^{10}$. En mi opinión, solo haciendo gala de una espléndida imaginación podrían reconocerse en estos cuadros formas físicas con referencias a los genitales de mujer. No hay por tanto

10 Mayayo, P.: Op. cit., pág. 91. 


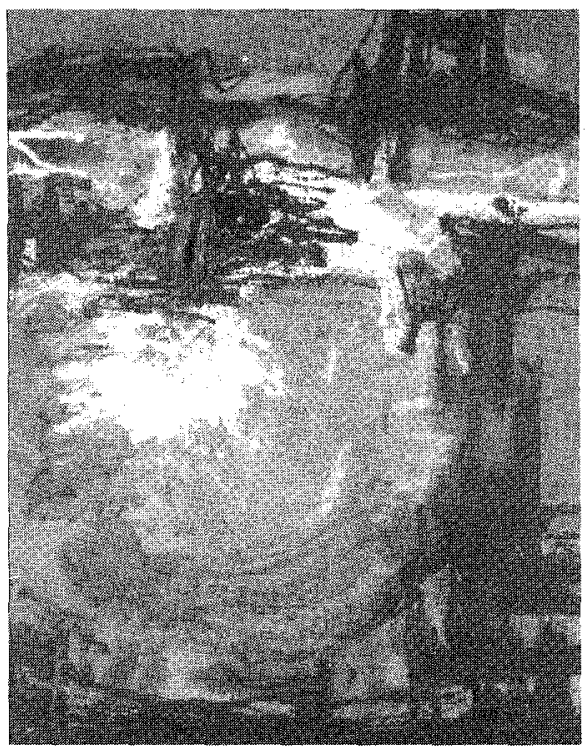

Fig. 9. Sapo panderetero, 1961.

una imaginería femenina en estas obras y el interés creativo de Juana Francés se centraría más en experimentar con un lenguaje y unos materiales nuevos, y extraerles todas sus cualidades expresivas. Retomando lo anterior, a partir de 1961 Juana comienza a incorporar cada vez más materiales de desecho como fragmentos de cocina, ladrillo, vidrio, piedras o conchas.

Todo esto da lugar a una especie de collages, con referencias a paisajes. No son paisajes perspectivos tradicionales sino «aperspectivos» ${ }^{11}$ y que resaltan el valor plástico de sus componentes. Más que pintura de paisaje es «un paisaje de la pintura" ${ }^{12}$. Paulatinamente estos elementos añadidos comenzarán a metamorfosearse y a insinuar facciones humanas, extraños rostros antropomórficos. Es el preludio de su siguiente serie El hombre y la ciudad. Como escribe la propia Juana en un texto autobiográfico «lentamente una nueva manera de ver al Hombre hace que vayan apareciendo en mis obras insinuaciones que pueden sugerir cabezas humanas» 13

11 Nieto Alcalde, V.: Op. cit., pág. 29.

12 Calle, R. de la: Op. cit., pág. 25.

${ }^{13}$ CORREDOR-MATHEOS, J.: «El arte de Juana Francés, entre la luz y las sombras», en Juana Francés 1924-1990: exposición homenaje, Alicante, Ayuntamiento de Alicante, Concejalía de Cultura, 1995, pág. 13. 


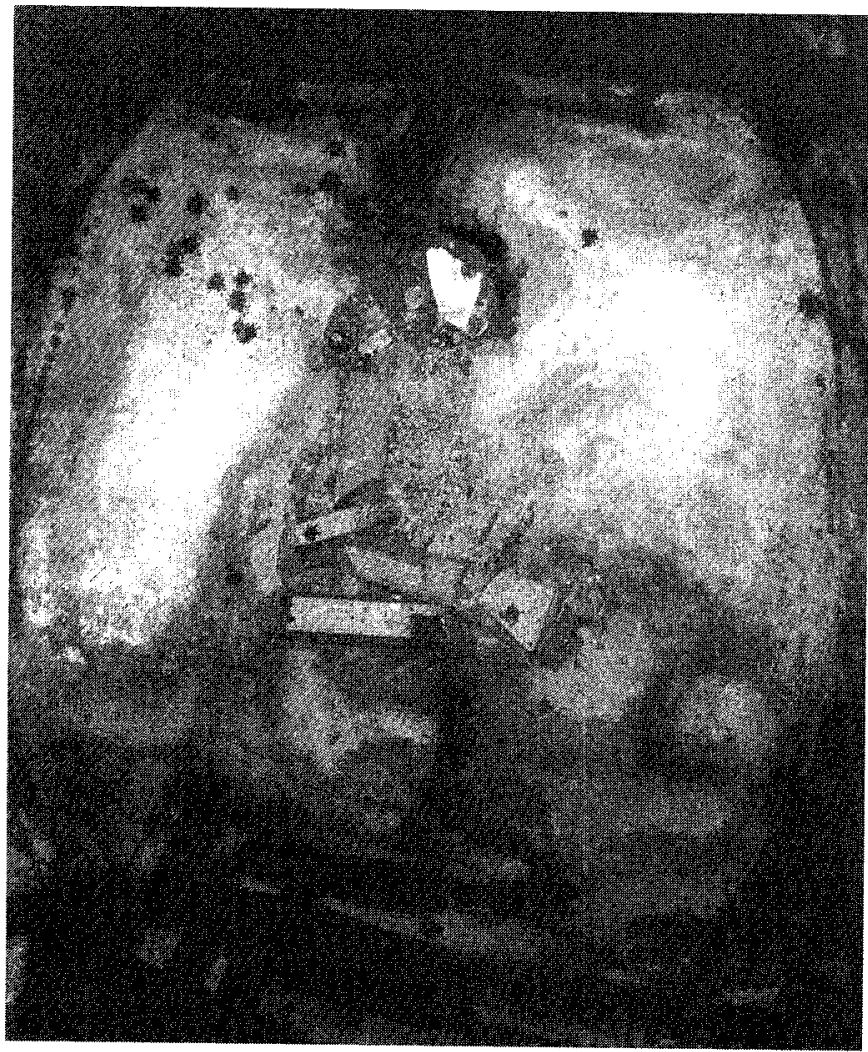

Fig. 10. Pozo blanco, 1962

En Pozo Blanco surge como una especie de nebulosa, una imagen circular y llena de luz, en la que se intuye la forma de un rostro humano y sus facciones: ojos, nariz y boca. Predomina en esta obra un gesto dinámico y un contrastado claroscuro que simula un rostro misterioso, sombrío, ambiguo; la imagen de un hombre diferente que inundará la siguiente etapa y que incluye varias subseries prolongándose hasta finales de la década de los setenta.

Tras el abandono paulatino del informalismo matérico (que no llega a ser total pues lo simultanea con nuevos estilos), Juana centrará su interés en el hombre urbano, abordado desde un punto de vista existencial. Aparece en estos años una preocupación constante por asuntos como el poder de los medios de comunicación o la tecnología (imágenes de teléfonos, televisiones e incipientes computadores campan a sus anchas). Para la artista, estos elementos conducen inexorablemente a la incomunicación, el aislamiento y la soledad. Es, como dice Víctor Nieto Alcalde, «la re- 
presentación de los símbolos del hombre, de alegorías de su soledad y de su existencia integrados en unos espacios lúgubres, expresivos de una opresión angustiosa». Pueblan las obras de este momento unos seres tétricos que llevan «los estigmas de la condición humana. Sufren, piensan, esperan, nos interrogan».14

Además de recurrir a colores casi siempre oscuros y planos, Juana sigue practicando el collage, o más bien el assemblage, pues "construye» las obras con restos "tecnológicos» como cables, tuercas, resortes, engranajes o dispositivos eléctricos, que, por lo general, inserta en unas formas ovaladas que se asemejan a cabezas. Es inevitable pensar en Kurt Schwitters, a quien la artista admiraba tras conocer su obra en una exposición sobre dadaísmo en el Museo de Arte Moderno de París.

Los títulos de las obras -algunos no exentos de ironía- son del todo elocuentes: Los ejecutivos, Incomunicado, Presidente de Consejo, Ser y Ecología, Situación coyuntural de la coyuntura o como la que aparece en la imagen Despacho del empleado n..$^{\circ}$ 3. Cabe destacar que muchos de estos títulos, se refieren a actividades laborales reservadas tradicionalmente a varones, y aún siendo imposible atribuir un sexo a estos extraños humanoides, surge irremediablemente la siguiente pregunta ¿pensaba Juana Francés, al representar estas figuras, en el hombre como especie humana? o ¿como hombre varón....?

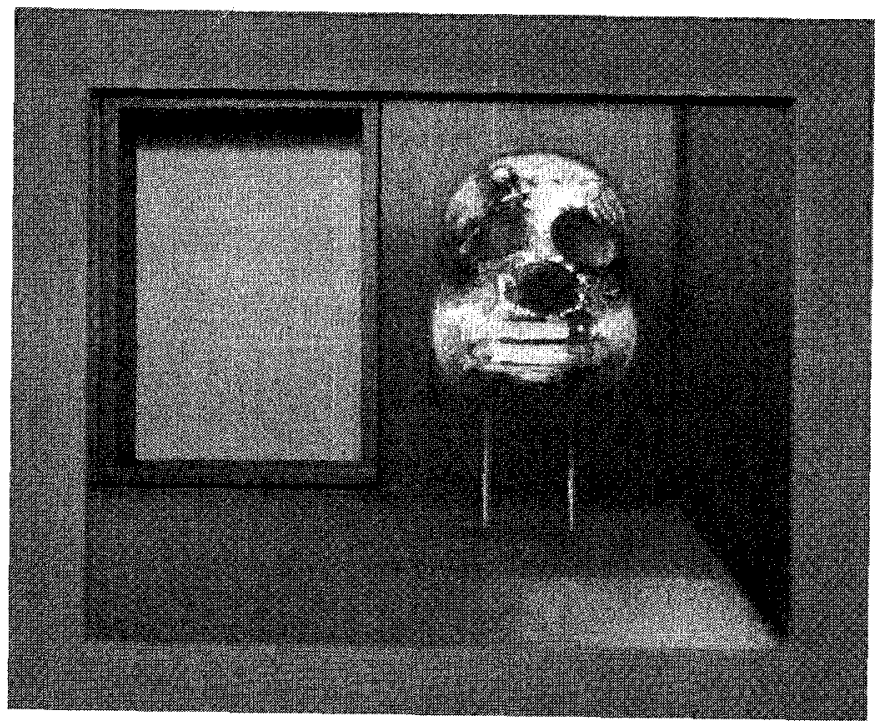

Fig. 11. Despacho del empleado n. ${ }^{\circ}$ 3, 1966.

14 Lassaigne, J.: Juana Francés, Palma de Mallorca, Palau Solleric, 1986. 


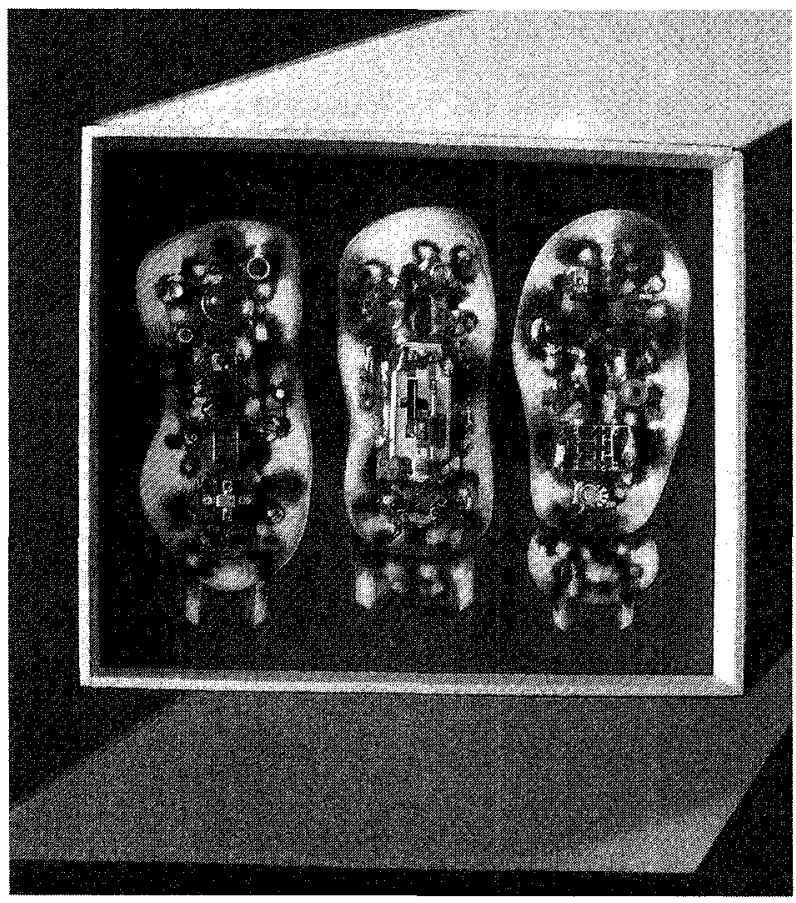

Fig. 12. Los ejecutivos, 1976.

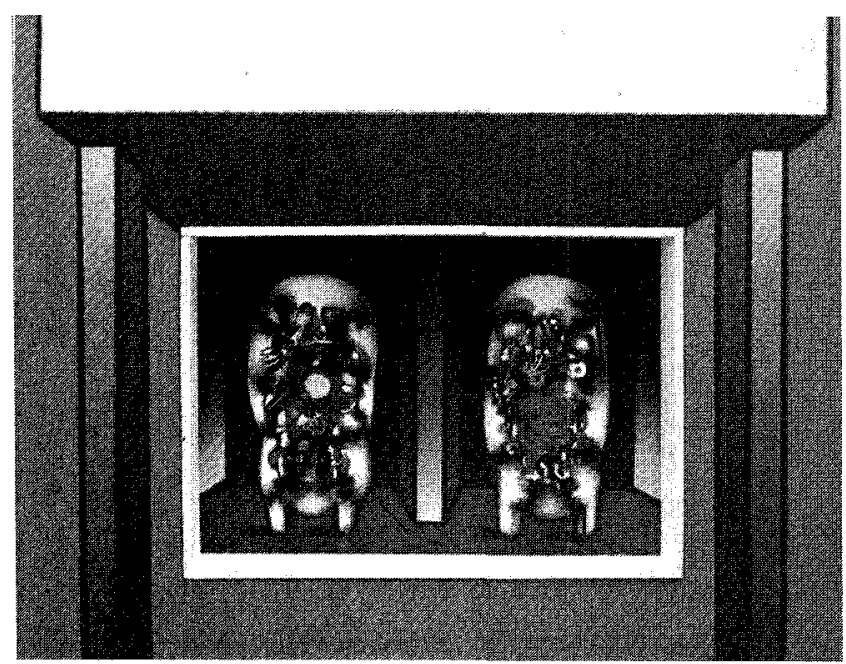

Fig. 13. Mandatarios, 1976. 


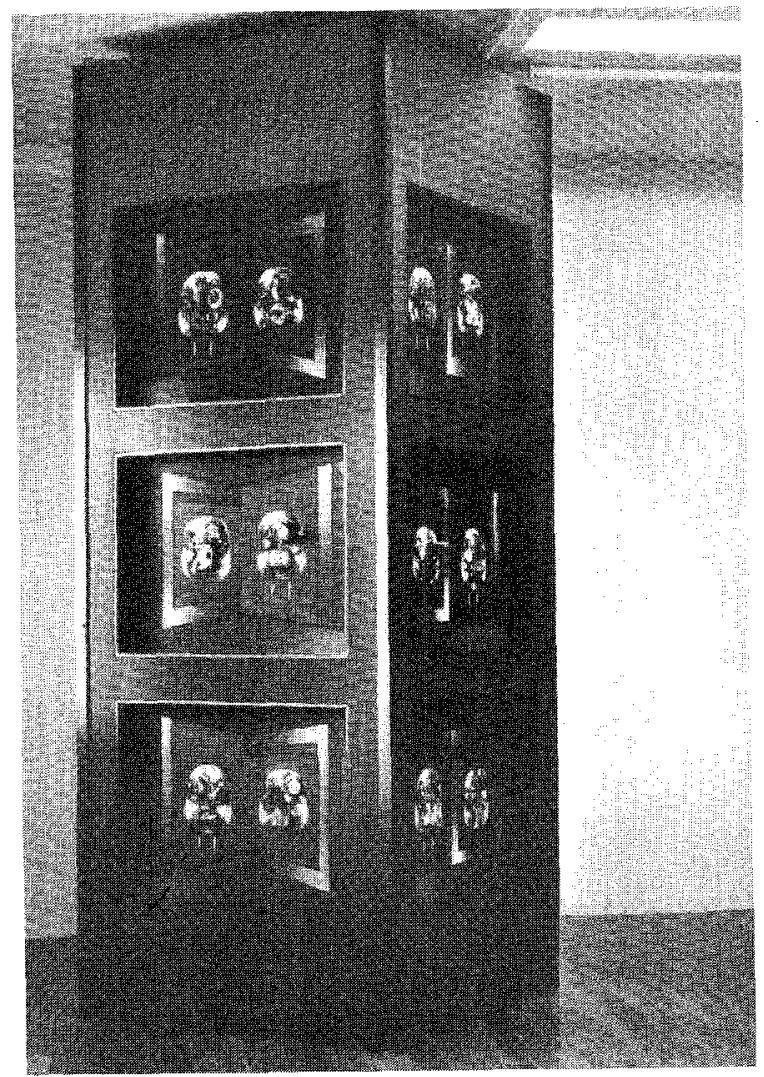

Fig. 14. Torre participación, 1974.

La mayoría de las fuentes consultadas para este trabajo - por cierto, en su mayoría escritas por hombres - , confirman que es un período en el que la artista alude metafóricamente a la condición humana. Desde luego muchas de estas obras, como he señalado anteriormente, sugieren situaciones generadas por el progreso de las sociedades occidentales contemporáneas, pero bajo mi punto de vista, y tras observar con atención algunas de ellas, es inevitable identificar a estos «personajes» (quizá condicionada por el mensaje de los títulos y la expresividad de las imágenes) con las altas estructuras de poder - un poder amenazante y opresor. Eduardo Westerdahl afirma que se trata de «una denuncia de los poderes opresivos que han anulado la libertad de la persona» ${ }^{15}$ _. Y surge nuevamente otra cuestión ¿quién ha detentado tradicionalmente el poder? La respuesta es sencilla...

15 WeSterdaht, E.: «La muerte del humanismo», en Juana Francés, Palma de Mallorca, Palau Solleric, 1986. 
Quizá Juana Francés no fuera consciente de que en estas obras aparece, de manera subliminal, el reflejo de un mundo hecho y protagonizado por hombres (varones) -como en Los Ejecutivos o Mandatarios-, que son alienados por las máquinas (también creadas casi con exclusividad por ellos), y que son capaces de oprimir a otros/as.

El escenario resultante de estas obras, como se puede ver en las imágenes adjuntas, puede recordar a una escena de ciencia ficción: un mundo desolado, lúgubre y desesperanzado.

El hombre y la ciudad evoluciona de modo irrefrenable en la serie TorresParticipación, si cabe, más dramática y expresiva, en la que continua indagando

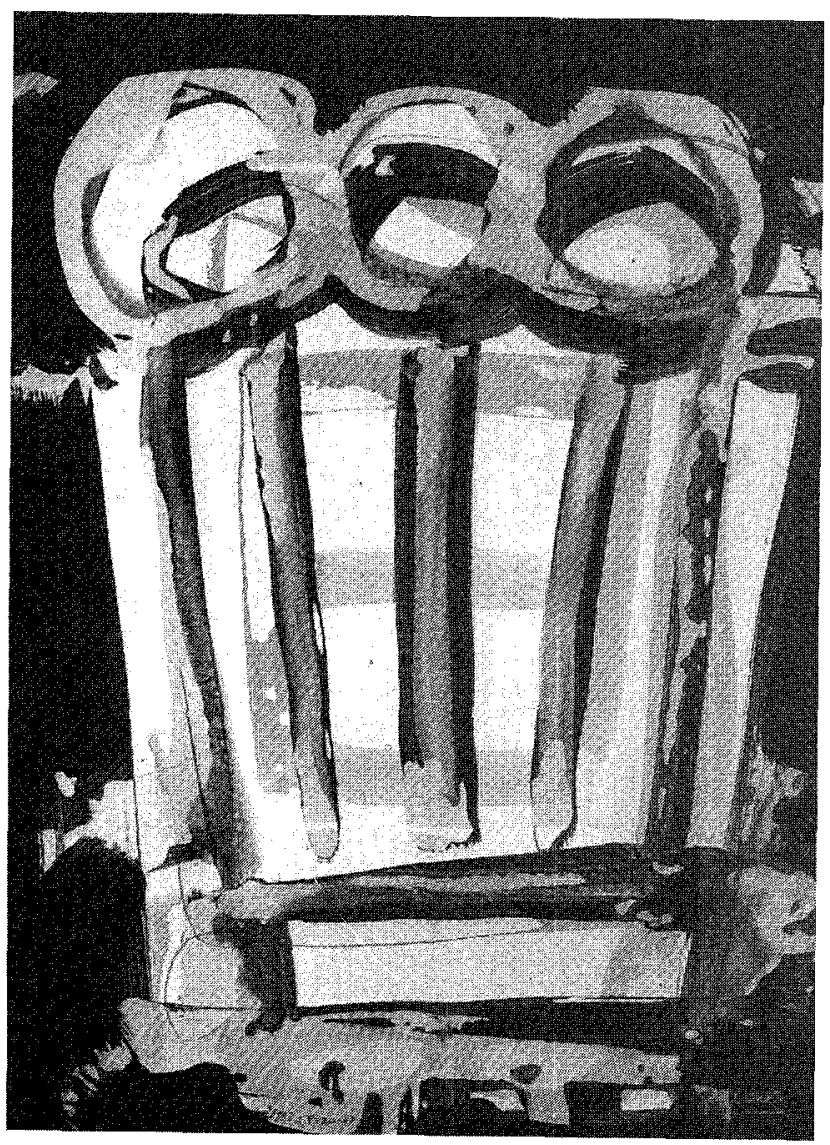

Fig. 15. Cometa, 1985. 


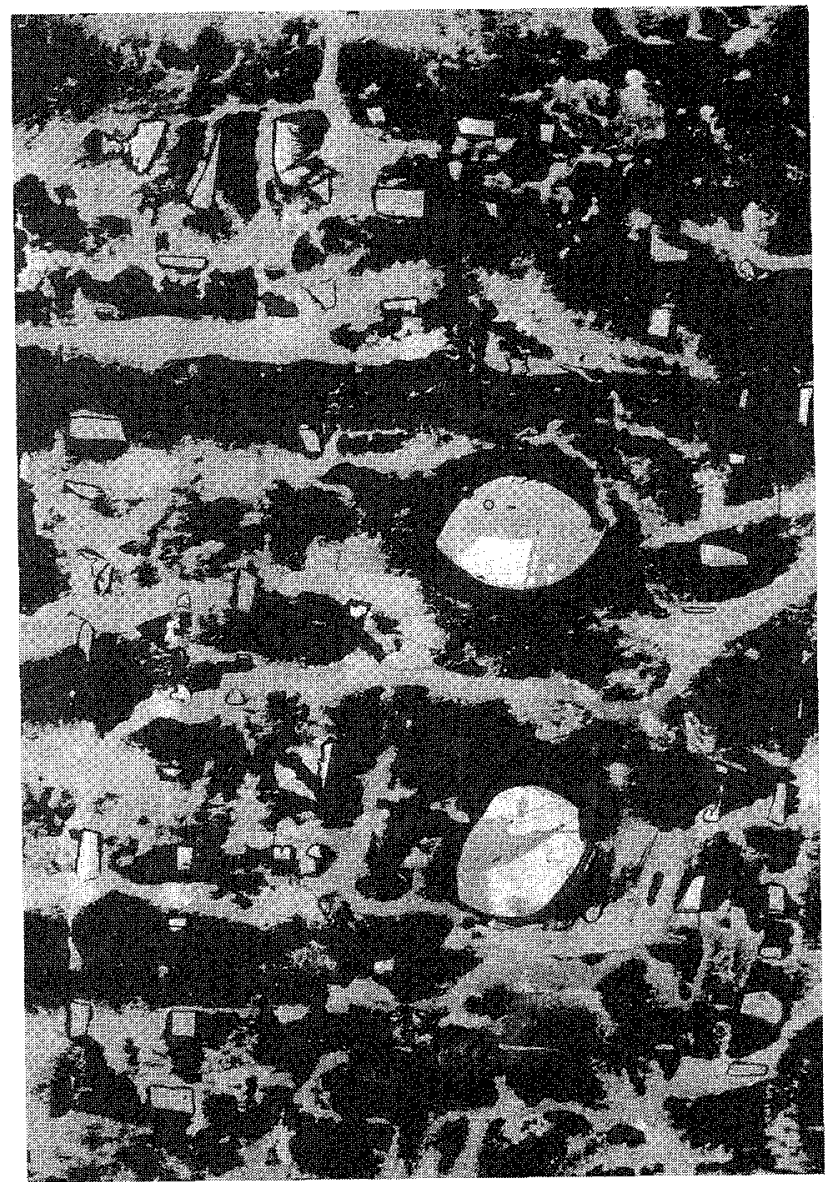

Fig. 16. Paisaje submarino, 1980.

sobre las cuestiones existenciales ya mencionadas. La obra se convierte en un objeto tridimensional, con forma de prisma rectangular, y de enormes dimensiones. Estas torres ¿parecen faros premonitorios de un futuro asolador?, ¿monumentales robots (¿masculinos?) que amenazan el destino de la humanidad?, o ¿estructuras fálicas que imponen su poder? Cada cual que juzgue libremente...

Al iniciarse la década de los años 80 , se produce un brusco giro en su trayectoria y Juana Francés da por terminado este momento pesimista y oscuro. Abandona esa pseudofiguración humanoide y retoma de nuevo y con más fuerza la abstracción. El pesimismo y la oscuridad dan paso a la luz, al color, al vitalismo. En algunas, predomina lo geométrico. Otras, son más gestuales, y de apariencia biológica. 
Se produce un retorno de la artista a la naturaleza. Esa naturaleza, que en el período creativo anterior había sido suprimida por la devastadora mano tecnológica del hombre, está representada por fondos submarinos, llenos de optimismo. Del mar sube al cielo y como un soplo de aire fresco nos presenta infinidad de coloristas cometas. Es una abstracción llena de lirismo. A pesar de que no es un momento fácil en su vida, - Pablo Serrano muere en 1985 - este conjunto de obras rezuman vitalidad y poesía. Parece que ahora el mundo es un lugar más amable. Como definió Camilo José Cela «en sus lienzos flota, como en la mar inmensa y dramática que ignora todas las fronteras, el sentimiento de que el universo se va creando a medida, que, un pie tras otro, vamos trazando el sendero que lo cruza de lado a lado ${ }^{16}$. La experiencia de la vida y del propio arte parece que hubieran serenado a la artista. Juana Francés, firme, decidida, apasionada, inquieta, incansable y libre, acabó su «lucha» y su arte en 1990.

${ }^{16}$ CELA, C. J.: Juana Francés, Palma de Mallorca, Palau Solleric, 1986. 